Weismann, the eminent zoologist, and Herr August Gruber publish an interesting article on their joint researches with regard to Daphniada, a family of Entomostraca. These investigations were principally confined to the species Moina, of which M. rectirostris has been well known for a long time. Weismann now describes two new varieties and names them $M$. brachiata and $M$. paratoxa. Other researches relate to the male forms of the species Macrothrix and Pasithea.

THE Fishes of LAKe Nicaragua.-Drs. Gill and Bransford have recently investigated the fauna of this lake and contributed a paper to the Philadelphia Academy of Natural Sciences. The element of especial interest is the association of characteristically marine forms with fresh-water types. Thus, together with cichlids and characinæ, none of which are marine, we have a species of megalops, a shark, and a saw-fish. A similar combination occurs in the Philippines, where, in a fresh-water lake, a saw-fish and a dog-fish are found. The megalops, however, is not known eisewhere in fresh water so isolated from the sea as Lake Nicaragua. These instances suggest caution in generalising on physiographical conditions from fossil remains. The most probable cause of such a combination is the detention and survival of salt-water fishes in inlets of the sea that have become isolated and gradually transformed into fresh-water lakes.

\section{SOLAR RADIATION AND SUN-SPOTS}

IN the year 1875 two articles by Mr. H. F. Blanford on the connection between solar heat and sun-spots appeared in the pages of NATURE (rol. xii. pp. 147 and I88), in which it was shown that Mr. Baxendell's conclusion that the sun's heat underyoes a periodical rariation coinciding directly with that of the spors, appeared to be supported by the evidence of observations of the blackbulb thermometer taken at certain stations in Bengal and the neiuhbouring provinces. My attention has been recalled to the subject by the almost complete failure of the rainy monsoon this year in Upper India, and by the excessively high temperature ever since the middle of June, and I have been thereby led to attempt to discover whether any evidence in favour of Mr. Baxendell's conclusion, or against it, is to be obtained from the registers of meteorological stations in Upper India. I have therefore gone over the registers of certain stations in the North-West Provinces and Oudh, where solar radiation temperatures have been recorded since 1869 , and at which not more than one change of instrument occurred in the interval 1869-1876. The inference I draw from these records is exactly the opposite of Mr. Blanford's. They do not afford any support to Mr. Baxendell's theory, but the energy of solar radiation appears from them to be most intense when the spots are fewest.

The reason of this discrepancy in the two sets of results will probably be found in the different modes of treatment we have adopted in extracting from the registers their evidence regarding this question. Mir. Blanford's treatment of the Silchar register, the results of which are given in his first paper, consisted in picking out certain "clear days" on which the mean serenity at 10 A.M. and 4. P.M. was 6-Ioths of the expanse, or more, tabulating the maximum temperatures of solar radiation for all these days in each month, and taking the average, neglecting the months of the south-west nonsoon which are almost entirely wanting in clear days, as above defined. The results of the examination of the Darjiling register, given in the second paper, were oblained by deducting from the three highest recorded temperatures of solar radiation in each half-month the corresponding maximum temperatures in shade, tabulating these differences for each month, and taking the averaye. Buth these devices, I think, introduce new elements of error, probably as great as those they were intended to obviate ; for, as Mr. Blanford himself points out, it constantly happens that the solar radiation thermometer records much higher temperatures when the sky is partly covered with broken cloud than when it is perfectly clear, the reason being, doubtless, that the instrument is then screened to a great extent from radiation into space, while the sun comes out from time to time, and exerts his full heating power upon it. I am therefore inclined to think that the somewhat higher radiation temperatures recorded at the Bengal stations in $1870,187 \mathrm{I}$, and 1872 were probably due to the larger number of partially cloudy days in those years as compared with the years immediately preceding and succeeding them.

In the clear atmosphere of Upper India the months of March, April, May, October, and November are generally almost without a cloud, the mean serenity at stations on the plains during those months being over 7 -Ioths. There can, therefore be little error in taking the mean excess of the maximum temperature of solar radiation above the maximum in shade during those months in each year, as the measure of the intensity of solar radiation during the year; for the two irregularities introduced by occasional cloudy days, prevention of direct radiation from the sun to the thermometer and prevention of radiation from the latter into space, will to some extent counterbalance each other.

The following table gives these yearly means for three stations :- Chakráta, lat. $30^{\circ} 40^{\prime} \mathrm{N}$, long $77^{\circ} 55^{\prime} \mathrm{E}$., elevation above sea-level, 7050 feet ; Roorkee, lat. $29^{\circ} 52^{\prime}$ N., long. $77^{\circ} 56^{\prime}$ E., elevation, 890 feet ; and Lucknow, lat. $26^{\circ} 50^{\prime}$ N., long. $81^{\circ} 0^{\prime}$ E., elevation 370 feet.

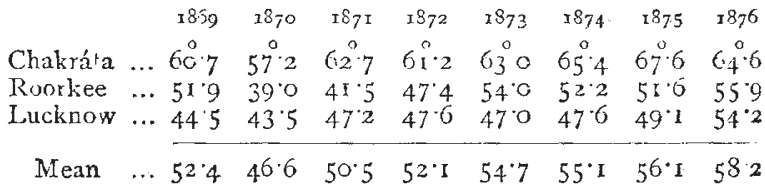

It will be seen that the lowest of these numbers is that corresponding to the year of sun-spot maximum, 1870, and the highest is that for 1876 , a year of very few spots.

Unfortunately none of the thermometers in $u$;e at these stations between 1869 and 1876 had been compared either with a standard or with the others, and as the instruments at some of the stations were in the meartime replaced, these results are doubtful within the limits of the error of such thermometers. This error probably never exceeds $5^{\circ}$, but the difference between the numbers for 1870 and I 876 , given in the table, amounts, on the average, to $11 \cdot 6^{\circ}$. It is believed, too, that during the whole perio 1 , I $869-76$, the thermometer at Chakráta was never changed, and one thermometer was in continuous use at Roorkee from 1872 to 1876 . The differences in the table must therefore be the effect either of a real variation in the sun's heat, or of a greater degree of absorption than usual during the wet and cloudy years, about the sun-spot minimum. Lest they should be attributed to this latter cause, I have examined the registers of the same three stations in much the same way as Mr. Blanford did that of Silchar, and find that owing to the proportion of cloud being su very small, especially in October and November, the results are very little changed. The mon hs of the suth-west monsoon, June, July, August, and September, and those of the win:er rains, December, January, and February, have been left out, and the only days counted during the remaining months are those on which the cluad proportion at four P.M., when the maximum thermometers were read, did not exceed 2 -roths. 'The only exception to this rule is the hill station Chakrata, where the cloud proportion for the spring months had to be fixed at one-halt. The exact temperature of solar radiation thus de trmined varies also in the way shown above, the only apparent tffect of the reatment being the introduction of blight 
irregularities for each station which almost disappear when the inean of the three is taken.

\begin{tabular}{|c|c|c|c|c|c|c|c|c|}
\hline & 7869 & $\dot{\mathbf{x}} 870$ & $18_{7} \mathrm{I}$ & $x 87^{2}$ & 1873 & 1874 & 1875 & \\
\hline 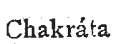 & $60^{\circ} 6$ & $57^{\circ} \cdot 6$ & $65^{\circ} \cdot 8$ & $6 \mathrm{I}^{\circ} 6$ & $64_{4}^{\circ} 2$ & $67^{\circ} \mathrm{o}$ & $68^{\circ} \cdot 3$ & \\
\hline & $5 \mathrm{II}_{4}$ & 38.8 & $42 \cdot 8$ & $50 \cdot 2$ & 53.9 & $50 \cdot 6$ & $5 \mathrm{I} \cdot \mathrm{I}$ & \\
\hline & 440 & $43^{\circ} \circ$ & $45^{\circ} 0$ & 487 & 47.8 & $5 \mathrm{I} \cdot \mathrm{I}$ & 4 & \\
\hline & & 6. & : & & & & & \\
\hline
\end{tabular}

Physicists appear to agree in the opinion that the temperature of parts of the solar atmosphere, as indicated by the great outbursts of hydrogen and other well-known phenomena, must be highest about the time of maximum spot-area; but I think the above figures will show that the question whether the amount of radiation which escapes into space is then at a maximum or not is still an open one. It must, at least, be admitted that the relative darkness of the spots is an indication of low temperature and consequent absorption. The registers of the Indian meteorological stations during the next ten years will probably give the data for determining the question, all the solar thermometers employed since the beginning of the present year having been carefully compared by exposing them side by side with an arbitrary standard before they were issued to the stations. The readings of one year will therefore be strictly comparable with those of another, notwithstanding the fact that breakages frequently occur.

It will probably be said that the very fact, now pretty well established, that rainfall is greatest in maximum sun-spot years argues increased evaporation and increased solar radiation during those years. The stations whose rainfall returns have been examined by Mr. Meldrum and those others who have worked at the subject are, however, not by any means uniformly distributed over the earth. The great majority of them are situated within or near the tropics, or in the maritime districts of temperate regions, and their more abundant rainfall in maximum sun-spot years might be easily explained by the diminished carrying power of the winds at that epoch of the solar cycle. Prof. Köppen has shown that the periods of maximum and minimum terrestrial temperature coincide approximately with the minima and maxima of sun-spots, and that both the maximum and minimum annual temperatures are reached somewhat so ner in the tropics than in the temperate zones. One would think, therefore, that the great convection currents of the atmosphere, depending on differences of temperatu re, would be least powerful a little after the maximum of sun-spots which is the period of heaviest tropical rainfall, and blow most strongly after the sun-spot minimum, the period of least rainfall in the tropics. The only data I know which would enable one to form an estimate of the rainfall of a large inland area in the temperate zone during a long term of years, are embodied in a diagram of the fluctuations of level of the North American lakes, given in a paper by Mr. G. M. Dawson, in NATURE, vol. ix. p. 506. The diagram shows a remarkable coincidence between the variations of the level of the lakes and those of the sun-spot area, and the inference Mr. Dawson draws from a comparison of the two curves appears to be that high water in the lakes is the result of great solar activity when the spot-area is large. Since the appearance of this paper in 1874 , it does not appear to have struck any of the readers of NATURE that, in every instance except one, high water in the lakes preceded the sun-spot maximum by two or three years, and, in like manner, the lowest level was reached several years before the sun-spot minimum; but a reference to the diagram will show that such is the case. It is evident, therefore, that high water in the lakes cannot be a consequence of numerous sunspots, but it may be a commutative effect of greater evaporation than usual and greater carrying power in the winds during the few years of high temperature succeeding the sun-spot minimum.
I have not at hand any means of ascertaining the relative velocities of the wind at European stations during the years about the maximum and minimum epochs of the solar cycle, but the anemometer records of Indian stations shows that the wind velocity varies directly with the temperature. The following table gives the mean velocity each year at five stations, as measured by a Robinson's small anemometer. The figures represent miles per diem :-

\begin{tabular}{|c|c|c|c|c|c|c|c|c|c|}
\hline & & i86g & 1870 & $187 \mathrm{I}$ & $x 872$ & 1873 & 1874 & 1875 & 1876 \\
\hline Calcutta & & - & $\therefore$ & 122 & $x 25$ & 133 & 140 & $\times 20$ & 33 \\
\hline Hazáribágh & $\ldots$ & - & - & 128 & 140 & 157 & 160 & 172 & \\
\hline Benares & $\ldots$ & 79 & 58 & 54 & 68 & 74 & 93 & Ii 6 & o \\
\hline Agra ... & $\ldots$ & $12 \mathrm{I}$ & 180 & 100 & 94 & 86 & 97 & 102 & IO3 \\
\hline Bareilly & $\ldots$ & 124 & II 4 & 89 & 64 & 67 & 72 & 75 & \\
\hline
\end{tabular}

If the yearly average for the first four stations be taken, it will be seen that there is a regular increase in the velocity of the wind from 1871 , the probable year of lowest terrestrial temperature, to 1876 , which was probably the hottest year of the period. It is, therefore, I think, at least possible that the excess of tropical and oceanic rainfall in maximum sun-spot years may be caused by precipitation near the place of evaporation, owing to the diminished force of the trade-winds and anti-trades at those periods, and that if the winter rainfall of Europe and America were examined, it might show an excess in minimum sun-spot years, derived from vapour brought by an unusually strong upper current from regions of great evaporation in the South Atlantic.

The registers of nearly twenty years show that the winter rainfall of India, north of the tropic, is probably subject to such a periodic variation, and if this surmise be verified in the future it may prove to be of the greatest economic importance. Last cold weather these rains were unusually abundant, and enabled the cultivators of Northern India to grow a spring crop sufficient not only for their own wants, but for export to Europe as well as to the famine-stricken districts of Madras and Bombay. Both this year and last the regular summer rains have been far below the average, and almost any day since last June the vapour that in an ordinary year would have come down to fertilise the soil might have been seen passing overhead in the form of light cirrus drifted by a strong south-west wind. The moist easterly current from the Bay of Bengal, from which a large proportion of the rainfall of the Gangetic valley is generally derived, has this year scarcely penetrated as far west as Benares. The natural consequence of this failure of the rains will be a famine in Northern India, unless, next cold weather, we get the heavy rains which the experience of past years leads us to expect.

A comparison of the mean temperature, vapour tension, humidity, and rainfall for the month of July in the years 1875 , I876, and 1877 , shows that the extraordinary dryness of the present year is the result not so much of the absence of aqueous vapour from even the lowest stratum of the atmosphere as of the abnormally high temperature which prevents its precipitation. This will be seen from the following table :-

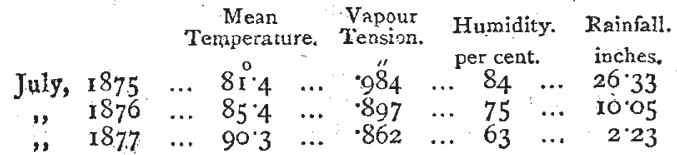

The figures in the table are deduced from observations taken at Allahabad four times daily, viz,, at 10 and 4 A.M. and P.M. The year 1875 was marked by unusually heavy local rains in July which laid a great part of the surrounding district under water, so a comparison of 1876 and 1877 with 1875 is hardly fair. The average rainfall of the month is 1465 inches.

Allahabad, August 29 